\title{
Biomechanical analysis of the penalty-corner drag-flick of elite male and female hockey players
}

\author{
CRISTINA LÓPEZ DE SUBIJANA ${ }^{1}$, DANIEL JUÁREZ ${ }^{2}$, JAVIER MALLO ${ }^{2}, \&$ \\ ENRIQUE NAVARRO ${ }^{2}$
} ${ }^{1}$ Social Sciences Applied to Physical Activity and Sport Department, Faculty of Physical Activity and
Sport Sciences, Technical University of Madrid, Madrid, Spain, and ${ }^{2}$ Sport Biomechanics Laboratory,
Faculty of Physical Activity and Sport Sciences, Technical University of Madrid, Madrid, Spain

\begin{abstract}
The aim of this study was to analyse the kinematic sequencing in the penalty-corner drag-flicks of elite male and female field hockey players of international calibre. Thirteen participants (one skilled male drag-flicker and six male and six female elite players) participated in the study. An optoelectronic motion analysis system was used to capture the drag-flicks with six cameras, sampling at $250 \mathrm{~Hz}$. Select ground reaction force parameters were obtained from a force platform which registered the last support of the front foot. Twenty trials were captured from each subject. Both player groups showed significantly $(p<0.05)$ smaller ball velocity at release, peak angular velocity of the pelvis, and negative and positive peak angular velocities of the stick than the skilled subject. Normalised ground reaction forces of the gender groups were also smaller than that of the skilled drag-flicker. By comparing these players we established that the cues of the skill level are a wide stance, a whipping action (rapid back lift) of the stick followed by an explosive sequential movement of the pelvis, upper trunk and stick.
\end{abstract}

Keywords: Hitting/batting, techniques, biomechanics, field hockey, kinematics, whipping action

\section{Introduction}

The penalty corner is one of the most important scoring plays in field hockey (Laird and Sunderland, 2003; Piñeiro, 2008). The drag-flick is used for shooting at goal with speed and precision (Chivers and Elliott, 1987) as it is more effective than other techniques such as hits and pushes when playing a penalty corner (McLaughlin, 1997; Piñeiro et al., 2007; Yusoff et al., 2008). According to the rules of hockey (FIH, 2009), there is no limitation regarding the maximum ball height when the first shot to score a goal is a push or a drag-flick. Some researchers have focused on strike techniques in field hockey (Chivers and Elliot, 1987; Kerr and Ness, 2006; Brétigny et al., 2008) but only two of them have analysed the drag-flick (McLaughlin, 1997; Yussoff et al., 2008), aiming to analyse kinematic parameters in relation to the level of experience of the players. Both studies were conducted using video photogrammetry with a sampling frequency of $50 \mathrm{~Hz}$. 
The drag-flick should follow the biomechanical pattern of throwing and hitting skills which aim to maximise the speed of the free end (distal) segment at release. In these skills, consecutive segments reach their maximum speed in series beginning with those furthest from the free end of the kinetic chain (Bartlett and Best, 1988; Putnam, 1993; Mero et al., 1994). McLaughlin (1997) noted that consecutive segmental rotations of the pelvis, upper trunk, and stick occurred in the drag-flick. For the push-in, Kerr and Ness (2006) found that the movement pattern is a combination of sequential and simultaneous segment rotations. Moreover, the major contribution to the ball speed during the drag-flick and the push-in were: the stance width, the distance between the front foot and the ball at the beginning of the double foot contact, and the angular velocities of the pelvis and upper trunk at ball release (McLaughlin, 1997; Kerr and Ness, 2006). However, there is a paucity of research on the kinematics of the pelvis, upper trunk, and stick in the penalty-corner drag-flick and no analytical study of the drag-flick techniques of female or elite hockey players of international calibre has been carried out. The aim of this study, therefore, was to analyse the kinematic sequencing in the drag-flicks of elite field hockey players.

\section{Methods}

Thirteen participants, one male skilled drag-flicker (36 years old; $66.5 \mathrm{~kg} ; 170 \mathrm{~cm} ; 29$ years of experience) of international calibre and six male $(19.8 \pm 1.0$ years; $70.4 \pm 9.7 \mathrm{~kg}$; $175.5 \pm 6.6 \mathrm{~cm} ; 7.3 \pm 3.1$ years of experience) and six female $(20.0 \pm 3.5$ years; $61.3 \pm 6.4 \mathrm{~kg} ; 165.4 \pm 0.5 \mathrm{~cm} ; 10.3 \pm 3.0$ years of experience) elite field hockey players participated in the study. The skilled drag-flicker was the drag-flicker of a top-level country for 15 years and was considered as the model to compare with. The elite male and female players were on the Spanish national team and the drag-flickers of their clubs in the Spanish Field Hockey First Division. Participants were requested to provide informed consent prior to participation. The University Ethics Committee approved the research protocol.

All the measurements were carried out in the Biomechanics Laboratory of the Faculty of Physical Activity and Sport Sciences, the Technical University of Madrid. A VICON optoelectronic system (Oxford Metrics, Oxford, UK) captured the drag-flicks with six cameras, sampling at $250 \mathrm{~Hz}$. The experimental space was $5 \mathrm{~m}$ long, $2.5 \mathrm{~m}$ wide and $2 \mathrm{~m}$ high and was dynamically and statically calibrated with an error of less than $2 \mathrm{~cm}$ and a static reproducibility of $0.4 \%$. A total of 42 retro-reflective markers ( 39 body markers and 3 stick markers; $14 \mathrm{~mm}$ diameter) were attached to anatomical landmarks following VICON's kinematics model (Vicon Motion Systems, 2003). The stick markers were placed at the beginning of the grip, at the toe of the shaft, and at the end of the shaft. All sticks had similar features (height: $93.8 \pm 1.2 \mathrm{~cm}$; mass: $584.6 \pm 80.1 \mathrm{~g}$; centre of mass position from the end of the shaft: $38.4 \pm 3.6 \mathrm{~cm}$ ), approved by the International Hockey Federation (2009). Raw data were filtered using quintic spline functions based on Woltring's CGV method for calculating the smoothing factor (Woltring, 1986).

As markers could not be placed on the ball, the ball velocity was estimated using photogrammetric DLT (Direct Linear Transformation) algorithms (Abdel-Aziz and Karara, 1971) after digitising the ball with two video cameras located at a $90^{\circ}$ angle. The video cameras were genlocked and sampled at $50 \mathrm{~Hz}$. Ground reaction force data were obtained from a Dinascan IBV force platform $(60 \mathrm{~cm} \times 35 \mathrm{~cm}$; sampling at $250 \mathrm{~Hz})$ positioned in the floor and located 4 meters away from the players' starting position. The $y$-axis of the platform was parallel with the shooting direction. The kinetic data were filtered with a fixed cut-off frequency of $50 \mathrm{~Hz}$ (Winter, 1990). 
After a specific warm-up, 20 good trials at their natural speed were captured from each subject. If a participant did not place his/her front foot on the force platform, the trial was rejected. The ball was placed by the subject approximately 1.5 to 2 meters away from the centre of the calibrated area. The drag-flick movement commenced once the front foot contacted the platform until 20 frames after the stick's peak positive angular velocity.

The ball velocity at release was obtained. The pelvis, upper trunk, and stick angles were calculated considering the line of the double foot contact as the $y$-axis, the $x$-axis $90^{\circ}$ from the $y$-axis to the right and the $z$-axis as the vertical axis (Figure 1). The angular velocities were computed from the angles formed by the trunk (shoulder line), pelvis (hip line), and stick with the $x$-axis on the $x y$ plane. The knee flexion angle was computed for the front leg only.

The following key events of the drag-flick were identified: T1 (front foot contact), T2 (peak negative angular velocity of the stick), T3 (maximum angular velocity of the pelvis), T4 (maximum angular velocity of the upper trunk), T5 (ball release), and T6 (peak positive angular velocity of the stick). The event times were normalised to the T1-T6 time. The stance width, drag-flick distance, and the front foot-ball distance at T1 were obtained and

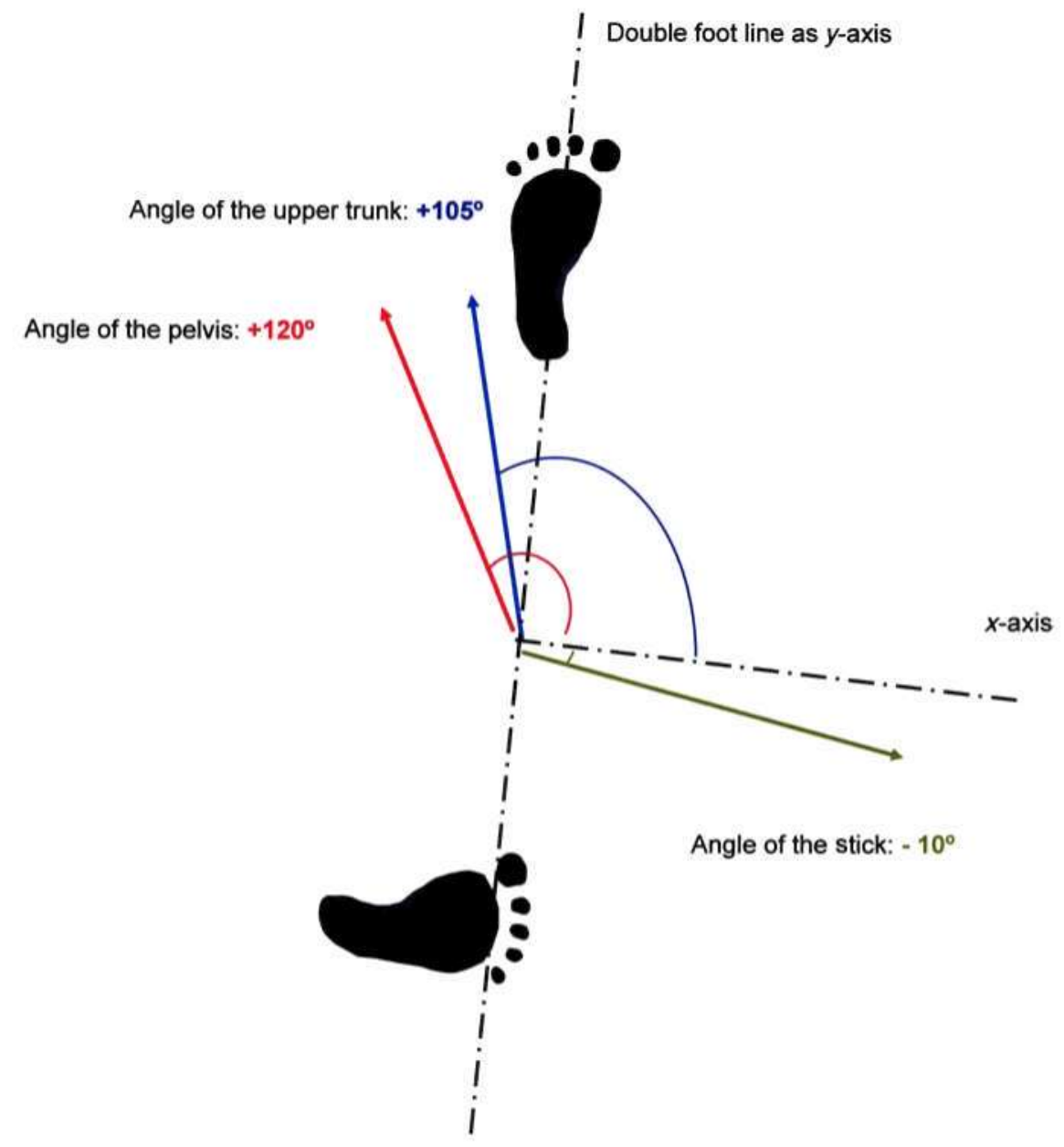

Figure 1. Exemplar angle parameters measured at double foot contact. 
Table I. Summary ( $M \pm S D$ ) of the peak angular velocity parameters (in $\%$ ).

\begin{tabular}{lccr}
\hline Parameter & Model drag-flicker & Male group & Female group \\
\hline Stick (negative) & $-390.5 \pm 41.9$ & $-124.6 \pm 112.2^{*}$ & $-192.2 \pm 87.5^{*}$ \\
Pelvis & $520.7 \pm 48.6$ & $344.3 \pm 63.4^{*}$ & $397.5 \pm 76.4^{*}$ \\
Upper trunk & $492.9 \pm 29.4$ & $473.4 \pm 90.2$ & $421.0 \pm 89.9^{*}$ \\
Stick (positive) & $1,890.1 \pm 72.8$ & $1,473.2 \pm 177.8^{*}$ & $1,168.1 \pm 223.0^{*}$ \\
\hline
\end{tabular}

*Significant differences with the drag-flicker at $p<0.05$.

normalised to player's height. The average velocity of the stick was also determined by dividing the drag-flick distance by the time from the double foot contact to $T 6$. The component peaks $(x, y$, and $z$ ) of the ground reaction force were normalised to player's body weight.

Statistical analysis was carried out using SPSS v.16 software (SPSS Inc., Chicago, IL, United States). Means and standard deviations of the study parameters were calculated. One- way analysis of variance (ANOVA) was used to analyse the differences in ball velocity at release for the three groups. Four one-way MANOVA were done with the group being the within factor and peak angular velocity parameters, normalised event times, the component peaks of the ground reaction force, and the distances and knee angles as multiple variables, respectively. The alpha level of significance was set at $p<0.05$ for all statistical tests.

\section{Results}

Both player groups $(21.9 \pm 1.7 \mathrm{~m} / \mathrm{s}$ for the male group and $17.9 \pm 1.7 \mathrm{~m} / \mathrm{s}$ for the female group) showed lower $(p<0.05)$ ball velocities at release than the skilled drag-flicker $(25.4 \pm 1.3 \mathrm{~m} / \mathrm{s})$.

The drag-flicker obtained higher peak angular velocities than both gender groups (Table I). These differences were significant in the peak negative angular velocity of the stick, and in the peak positive angular velocities of the pelvis and the stick. When comparing the positive peak angular velocity of the upper trunk rotation, the skilled drag-flicker showed significant differences with the female group but not with the male group. While both the male and female groups increased their positives peaks angular velocities from proximal to distal, the drag-flicker achieved higher angular velocity of the pelvis than the upper trunk.

The kinematic sequence of the peak angular velocities was similar between the skilled drag-flicker and the male group (T2-T3-T4-T5-T6 sequence), whereas the female group showed a different sequence (T3-T2-T4-T6-T5 sequence) (Table II). Significant differences were observed in the normalised event times between the female group and the

Table II. Summary ( $M \pm S D$ ) of the normalised event times (in $\%$ of T1-T6 time).

\begin{tabular}{lccr}
\hline Event & Model drag-flicker & Male group & Female group \\
\hline T2 & $34.0 \pm 9.1$ & $37.9 \pm 10.7$ & $48.9 \pm 15.1^{*}$ \\
T3 & $55.1 \pm 3.0$ & $49.3 \pm 9.4$ & $28.1 \pm 27.7^{*}$ \\
T4 & $66.8 \pm 6.1$ & $57.1 \pm 8.1^{*}$ & $61.9 \pm 9.5^{*}$ \\
T5 & $96.2 \pm 4.5$ & $98.8 \pm 4.8$ & $101.3 \pm 7.1^{*}$ \\
\hline
\end{tabular}

*Significant differences with the drag-flicker at $p<0.05$.

Abbreviations: $T 1$, foot contact; $T 2$, peak negative angular velocity of the stick; $T 3$, peak pelvis angular velocity; $T 4$, peak upper trunk angular velocity; $T 5$, ball release; $T 6$, peak positive angular velocity of the stick. 
Table IIL. Summary $(M \pm S D)$ of the distance and angle parameters.

\begin{tabular}{lccc}
\hline & Model drag-flicker & Male group & Female group \\
\hline Stance width $(\mathrm{m})$ & $1.49 \pm 0.05$ & $1.55 \pm 0.09$ & $1.32 \pm 0.08$ \\
Normalised stance width $(\mathrm{BH})$ & $0.88 \pm 0.03$ & $0.88 \pm 0.05$ & $0.80 \pm 0.04^{* 5}$ \\
Football distance at T1 $(\mathrm{m})$ & $1.00 \pm 0.06$ & $1.23 \pm 0.24$ & $0.93 \pm 0.18$ \\
Normalised foot-ball distance at T1 $(\mathrm{BH})$ & $0.67 \pm 0.05$ & $0.79 \pm 0.15^{*}$ & $0.71 \pm 0.13$ \\
Drag distance $(\mathrm{m})$ & $2.01 \pm 0.06$ & $2.42 \pm 0.31$ & $1.70 \pm 0.38$ \\
Normalised drag distance $(\mathrm{BH})$ & $1.18 \pm 0.07$ & $1.38 \pm 0.16^{*}$ & $1.03 \pm 0.22^{* 5}$ \\
Drag-flick velocity $(\mathrm{m} / \mathrm{s})$ & $11.6 \pm 0.4$ & $11.0 \pm 0.6^{*}$ & $8.6 \pm 0.9^{*}$ \\
Knee angle at Tl $(9)$ & $165.0 \pm 1.7$ & $156.1 \pm 7.6^{*}$ & $154.7 \pm 6.6^{*}$ \\
Knee angle at T6 $(9)$ & $131.2 \pm 2.2$ & $114.1 \pm 10.9^{*}$ & $109.6 \pm 17.9^{*}$ \\
\hline
\end{tabular}

* Significant differences with the drag-flicker at $p<0.05$.

Significantly different with the male group at $p<0.05$.

Abbreviations: $\mathrm{BH}$, body height; $\mathrm{T} 1$, foot contact; $\mathrm{T} 6$, peak positive angular velocity of the stick.

skilled drag-flicker at all events. The male group only showed a significant difference with the model drag-flicker at T4 (peak upper trunk angular velocity) (Table II).

Stance width was shorter in the female group than in the skilled drag-flicker (Table III). The female group showed significant differences with the drag-flicker and with the male group in the normalised stance width. The normalised drag distance was significantly longer in the male group than in the skilled drag-flicker and in the female group. The normalised foot-ball distance at $\mathrm{T} 1$ was significantly smaller in the model drag-flicker than in the male group. The drag-flick velocity of the stick was significantly larger for the drag-flicker than male and female group. Knee flexion angle was significantly smaller for the drag-flicker and he also showed smaller angle change than both gender groups.

The drag-flicker showed larger peak ground reaction forces in all components and the resultant than both gender groups (Table IV).

\section{Discussion}

The kinematic parameters studied highlighted the lower level of performance of the female group. The drag-flicker showed data that were similar to the male group but the differences with the female group were more evident.

The ball velocities obtained in this study were larger than those $(19.1$ to $21.9 \mathrm{~m} / \mathrm{s})$ reported by McLaughlin (1997) and those $(19.6$ to $27.8 \mathrm{~m} / \mathrm{s}$ ) reported by Yussoff et al. (2008). McLaughin (1997) compared a model flicker with regional hockey players, while Yussoff et al. (2008) registered 19 shots from five international hockey players during the $10^{\text {th }} \mathrm{Men}$ 's Hockey World Cup 2002. The sample of the present study consisted of international hockey players so the values were closer to the international drag-flickers (Yussoff et al., 2008).

Table IV. Summary ( $M \pm S D$ ) of the peak ground reaction force parameters (in body weight).

\begin{tabular}{lccr}
\hline Component & Model drag-flicker & Male group & Female group \\
\hline X & $0.54 \pm 0.06$ & $0.38 \pm 0.09^{*}$ & $0.40 \pm 0.14^{*}$ \\
Y & $1.45 \pm 0.07$ & $1.09 \pm 0.24^{*}$ & $0.85 \pm 0.22^{*}$ \\
$Z$ & $2.21 \pm 0.07$ & $1.94 \pm 0.24^{*}$ & $1.57 \pm 0.31^{*}$ \\
Resultant & $2.69 \pm 0.09$ & $2.27 \pm 0.31^{*}$ & $1.84 \pm 0.37^{*}$ \\
\hline
\end{tabular}

*Significant differences with the model drag-flicker at $p<0.05$. 
The angular velocities obtained in this study were also larger than those reported previously: $155-175 \%$ for the pelvis and $260-265^{\circ} / \mathrm{s}$ for the upper trunk (McLaughin, 1997). Our data were in accordance with Kerr and Ness (2006) where the experienced players achieved $439 \%$ and $604 \%$ for the pelvis and the upper trunk, respectively, and the inexperienced players achieved $363 \%$ and $558 \%$, respectively.

The timing of the movement showed that after the double foot contact the drag-flicker and the male group followed a similar kinematic sequence while the female group's timing was different. As it was shown from the normalised event times (Table $\amalg$ ), the female group produced their peak angular velocity of the pelvis earlier than the peak negative angular velocity of the stick. According to Kerr and Ness (2006) it is reasonable for the model drag-flicker and the male group to achieve the peak positive angular velocity of the stick after the ball release, as a result of the decreased action of the external torque at the end point of the stick, elimination of the friction, and decreased moment of inertia.

In order to enhance the dragging action the players moved the stick clockwise (backward; Figure 1) before the final acceleration (forward). This movement is known as the 'whipping action'. The whipping action of the stick is characterised by the peak negative angular velocity of the stick. Both player groups showed smaller peak negative angular velocities of the stick than the skilled drag-flicker in this study.

The drag-flick stance widths were similar to $1.23 \mathrm{~m}$ (for the group) and $1.42 \mathrm{~m}$ (for the model flicker) reported by McLaughlin (1997) and shorter than those (1.55 to $1.82 \mathrm{~m}$ ) reported by Yussoff et al. (2008). The football distance at the beginning of the double foot contact (T1) of the skilled drag-flicker and both gender groups was found to be longer than those $(0.73 \mathrm{~m}$ for the group and $0.81 \mathrm{~m}$ for the model drag-flicker) reported in the study by McLaughlin (1997). Our male-group values were similar to the 1.01 to $1.66 \mathrm{~m}$ range presented by Yussoff et al. (2008). The drag-flick distances were longer than those in the study of McLaughlin (1997) (1.36 m for the group and $1.47 \mathrm{~m}$ for the model drag-flicker) and similar to the data $(1.65$ to $2.24 \mathrm{~m}$ ) reported by Yussoff et al. (2008). These results may reflect how much this skill has improved during the last decade by increasing the dragging distance. We found a significant difference between the model and the male group regarding the normalised drag-flick distance. We speculate that the drag-flick distances can be affected by the anthropometric characteristics of the players and normalised values are more suitable to apply to different player groups.

Our drag-flick velocity showed similar values to those of the national league players $(9.7 \mathrm{~m} / \mathrm{s})$ and the model flicker $(12.2 \mathrm{~m} / \mathrm{s})$ from the study of McLaughlin (1997) but smaller than the values $(12.8$ and $19.8 \mathrm{~m} / \mathrm{s})$ from Yussoff et al. (2008).

Chivers and Elliott (1987) measured a $150^{\circ}$ angle in the front knee at impact in the 'hit' skill. The smaller (more flexed) knee angle values obtained in this study can be explained by the difference in the skill. Whereas the player maintains an upright position and uses a full backswing in the hit, the player must enhance the base of support and acquire a lower position of the centre of gravity to release the ball during a drag-flick in accordance to the official rules of the game. The skilled drag-flicker had less change in the front lnee angle and registered significantly larger normalised ground reaction forces peaks than the player groups in this study.

\section{Conclusion}

In summary, we have shown the kinematic sequence of the drag-flick of field hockey players of international calibre. We have identified significant differences between the model dragflicker and both elite player groups in the peak negative and positive angular velocities of the 
stick, and in the peak angular velocity of the pelvis, and in the ground reaction force registered. From the inter-group comparisons, we conclude that the cues of the skill level are a wide stance, a whipping action (rapid back lift) of the stick followed by an explosive sequential movement of the pelvis, upper trunk, and stick.

\section{Acknowledgements}

This study was financially supported by the Spanish Sport Council.

\section{References}

Abdel-Aziz, Y. I., and Karara, H. M. (1971). Direct linear transformation from comparator coordinates into object space coordinates in close range photogrammetry. Paper presented at the ASP Symposium on close range photogrammetry, Fall Church.

Bartlett, R. M., and Best, R. J. (1988). The biomechanics of javelin throwing: A review. Fournal of Sport Sciences, $6(1), 1-38$.

Brétigny, P., Seifert, L., Leroy, D., and Chollet, D. (2008). Upper-limb kinematics and coordination of short grip and classic drives in field hockey. Journal of Applied Biomechanics, 24 (3), 215-223.

Chivers, L., and Elliott, B. (1987). The penalty corner in field hockey. Excel, 4(1), 5-8.

International Hockey Federation. (2009), Rules of hockey from $1^{\text {sr }}$ May 2009. World Hockey. Lausanne: I.H.F.

Kerr, R, and Ness, K. (2006). Kinematics of the field hockey penalty corner push-in. Sports Biomechanics, 5 (1), $47-61$.

Laird, P, and Sutherland, P. (2003). Penalty corners in field hockey: A guide to success. International fournal of Performance Analysis in Sport, 3 (1), 19-26.

McLaughlin, P. (1997). Three-dimensional biomechanical analysis of the hockey drag fick: full report. Belconnen, A.C.T., Australia: Australian Sports Commission.

Mero, A., Komi, P. V., Korjus, T., Gregor, R. J., and Navarro, E. (1994). Body segment contribution to javelin throwing during final thrust phases. Fournal of Applicd Biomechanics, 10 (2), 166-177.

Piñeiro, R. (2008). Observación y análisis de la acción de gol en hockey hierba [Observation and analysis of the scoring plays in field hockey]. Sevilla: Wanceulen.

Piñeiro, R., Sampedro, J., and Refoyo, I. (2007). Differences between international men's and women's teams in the strategic action of the penalty corner in field hockey. International fournal of Performance Analysis in Sport, 7 (3), $67-83$.

Putnam, C. A. (1993). Sequential motions of body segments in striking and throwing skills: description and explanations. Fournal of Biomechanics, 26, 125-135.

Vicon. (2003). Vicon user manual. Oxford, UK: Oxford Metrics.

Winter, D. A. (1990). Biomechanics and motor control of human movement. Waterloo, Ontario, Canada: WileyInterscience Publication.

Woltring, H. J. (1986). A Fortran package for generalized, cross-validatory spline smoothing and differentiation. Advances in Engineering Software and Workstations, 8(2), 104-113.

Yusoff, S., Hasan, N., and Wilson, B. (2008). Tree-dimensional biomechanical analysis of the hockey drag flick performed in competition. ISN Bulletin, National Sport Institute of Malaysia, I (1), 35-43. 